\title{
A Positioning Map and Future Research Agenda of Collaborative Consumption
}

\author{
Damayanti Octavia ${ }^{1}$, Gatot Yudoko ${ }^{2}$, Reza Ashari Nasution ${ }^{3}$ \\ School of Business and Management ITB, Bandung, 40132 \\ Faculty of Economics and Business, Telkom University, Bandung, 40257 \\ damayanti_octavia@sbm-itb.ac.id, gatot@sbm-itb.ac.id, reza@sbm-itb.ac.id
}

Diterima: $14 / 04 / 2020$.

Direview: $21 / 04 / 2020$.

Diterbitkan: 31/08/2020.

Hak Cipta (C) 2020 oleh Penulis (dkk) dan Jurnal Sosial Humaniora (JSH)

*This work is licensed under the Creative Commons Attribution International License (CC BY 4.0). http://creativecommons.org/licenses/by/4.0/

\section{Subject Area: Economy}

\begin{abstract}
Collaborative consumption $(C C)$ is the new business model which overlaps with the concept of sharing economy (SE). However, CC has some unique characteristics that are not found in SE. This study aims to compare the two based on three dimensions: compensation, ownership, and platform. ECommerce (EC) is included into the comparison in order to show that CC is actually a combination of $S E$ and $E C$, thus covering a larger set than the other two concepts. The method used in this study is the literature study. The methods used CC concept manually and VOSviewer software to reassure and explore the unique characteristics of CC in comparison with SE and EC. The positioning map based on two dimensions: compensation and platform generate six business models that can be represented the characteristic of CC, $S E$, and EC. The six models are: (1) platform-based and monetary compensation; (2) platform-based and non-monetary compensation; (3) platform-based and without compensation; (4) non-platform-based and monetary compensation; (5) non-platform-based and non-monetary compensation; (6) non-platform-based and without compensation. The last dimension is ownership describe that CC activity is including exchange-based and access-based activity, while SE provides access-based activity only and EC offering exchange-based activity. The study also aims to discover the unique characteristics of $C C$ that will be used as the basis for developing a future research agenda of $C C$.
\end{abstract}

Keywords: Collaborative Consumption; Sharing Economy; E-Commerce.

\section{Introduction}

Collaborative Consumption (CC) has grown in the past ten years to become a popular topic of research (Botsman \& Rogers, 2010a). Generally speaking, CC involves the technology-based interaction among different actors (provider, facilitator, and obtainer) who initiate resource exchange for gaining monetary or non-monetary compensation.

Research potentials of CC might be obscured because of overlapping scope with another similar concept, which is Sharing Economy (SE) (Becker-Leifhold, 2018; Belk, 2014; Gheitasy, AbdelnourNocera, \& Nardi, 2015; Hamari, Sjöklint, \& Ukkonen, 2016; Martin, 2016; Möhlmann, 2015; Plenter, Fielt, Von Hoffen, Chasin, \& Rosemann, 2017). Both CC and SE share several characteristics. First of all, they use the Internet as a tool to mediating supply and demand. Secondly, both CC and SE have the goals to increase efficiency and decrease pollution by renting or sharing idle sources (goods, foods, 
services), not owning a new product or service (Ganapati \& Reddick, 2018). Lastly, the emergence of SE and CC had the same motives: 1) financial motives (Davidson, Habibi, \& Laroche, 2018; Heinrichs, 2013). and 2) environmental awareness motives (Hamari et al., 2016; Jiang \& Tian, 2018).

Our literature study indicates a rising popularity of SE as seen in Figure 1. The first article on sharing economy appeared in 1998, whereas the term of CC was firstly mentioned in 1978 (Felson \& Spaeth, 1978). The authors defined $\mathrm{CC}$ as the activity to collectively use or consume goods or foods. They gave some examples of $\mathrm{CC}$ in a family, in which all family members can share the use of a laundry machine, having dinner, lunch, or breakfast, along with all family members or friends. Despite of its earlier appearance, articles on CC lagged behind those of SE since 2012. The gaps is getting wider and nowadays scholars tend to consider CC as a subset of SE (Dreyer, Lüdeke-Freund, Hamann, \& Faccer, 2017; Guyader, 2018).

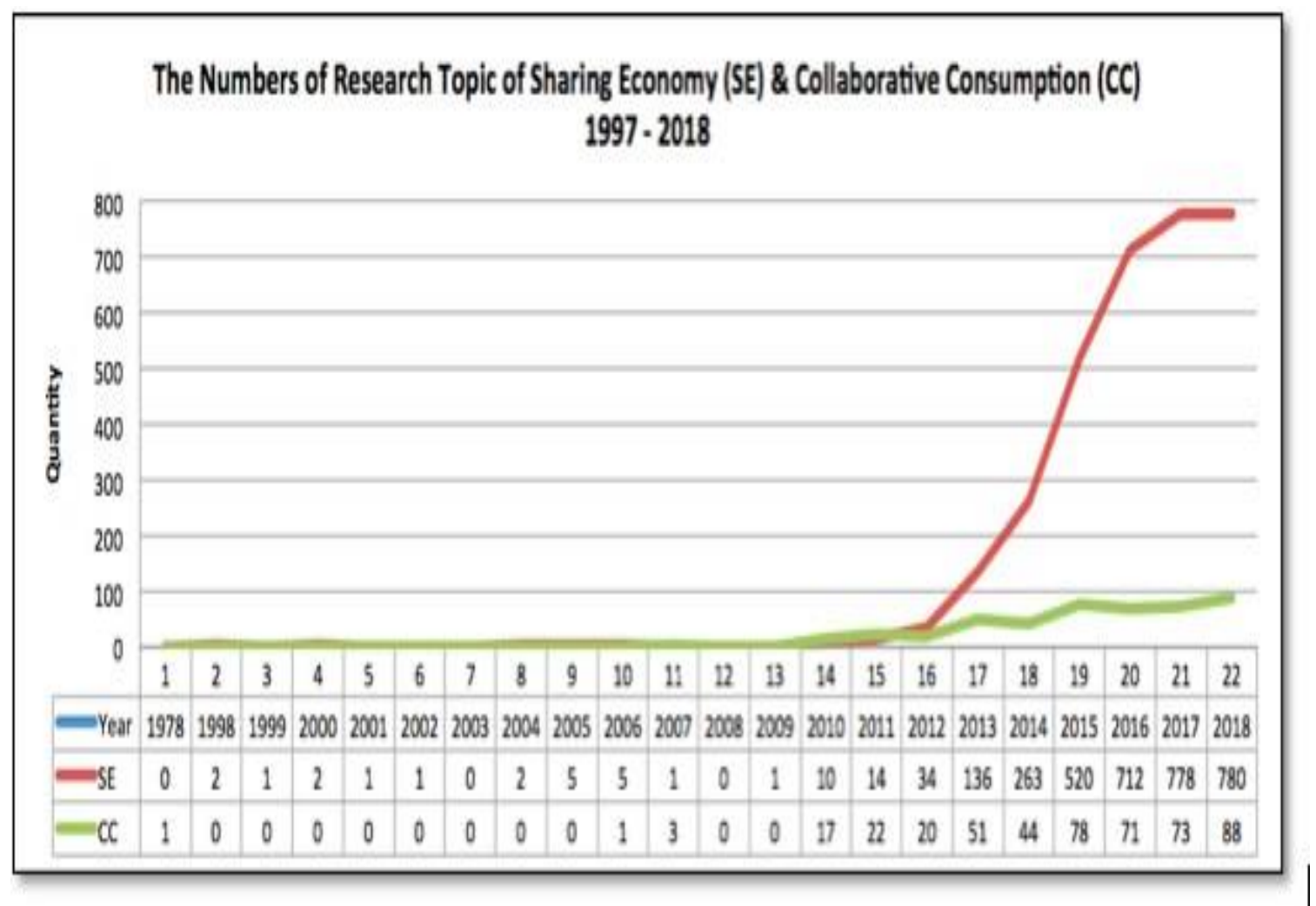

Source: Author calculations

Actually, CC has some unique characteristics that are not found in SE. In this paper, we compare the two along three dimensions Cherry \& Pidgeon (2018): compensation, ownership, and platform usage. Within the compensation dimension, we can distinguish the two in terms of the orientation toward profit, i.e. profit-oriented or non- profit oriented. In the ownership dimension, we can differentiate the two into two groups: access-based versus exchange-based. Access-based ownership refers to one party providing access to resources that can be used temporarily by another party. Whereas exchange-based ownership is related to the transfer of ownership from one party to another party. The last dimension is platform, of which we can differentiate the online activities into two: platform-based activities and non-platform-based activities. By using these three dimensions, we can discover the unique characteristics of $\mathrm{CC}$ so that it opens opportunities to develop research on $\mathrm{CC}$ in the future. 
The current study aims to: (1) study the characteristics of CC and SE based on three dimensions: compensation, platform, and ownership as well as their similarities and differences; (2) discovering the unique characteristics of $\mathrm{CC}$ that will be the basis for developing a research agenda regarding $\mathrm{CC}$ in the future. The authors included Electronic Commerce (EC) into the comparison in order to show that $\mathrm{CC}$ is actually a combination of SE and EC, thus covering a larger set than the other two concepts. This paper has five sections. After the introduction is an explanation of the methodology to collect relevant articles on CC, SE, and EC. The articles are used to develop an understanding toward EC, SE, and CC so that we can identify the similarities and differences among those seemingly related terms. This can be found in the literature review section. The fourth section contains a discussion of the findings. There we put CC, SE, and EC in a framework that shows the delineation of the three concepts. The last section contains the conclusions of this paper and also some research agenda that may be executed to extend our knowledge of $\mathrm{CC}$ in the future.

\section{Literature Review}

\section{E-Commerce}

EC is a virtual place using the Internet or another network in which seller and buyer, indirect meeting to make a transaction (Turban et al., 2018). According to Dave Chaffey, Tanya Hemphill (2019), EC refers to all electronically mediated information exchanges between an organization and its external stakeholders. External stakeholders can be seen from buy-side and sell-side. The external stakeholder in the buy-side is supplier and other partners. While sell- side, customer is the external stakeholder for organization. Laudon \& Traver (2016) argue that EC is the use of the Internet, the Web, and mobile apps and browsers running on mobile devices to transact business. From several definitions of EC, we argue that $\mathrm{EC}$ is digital commerce involves two or more parties to exchange the resources of each other.

In the 1990s, the Internet presence transforms commerce from physical to virtual transaction and today's known as electronic commerce (E-Commerce). E-Commerce (EC) topic becomes interestingly to discuss and investigate by most scholars. Business, management, accounting, and social science are the most attractive subject area for EC. The following figure describes the E-commerce publication trend from 1989 to the present.

Figure 2. E-Commerce Publications Trend

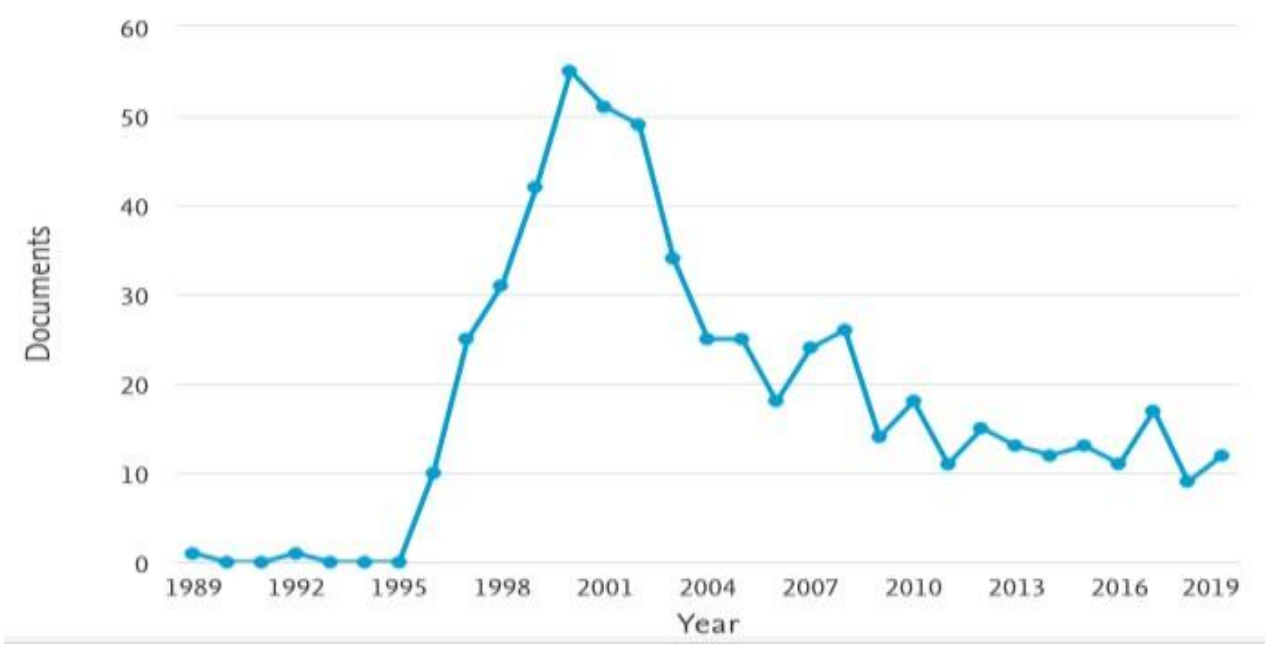


According to the figure (2), EC publication started to grow in 1995, and the culmination EC publication was in the 2000s. Then the EC research tends to decrease in 2001s until now. It means that the trend of EC research has already saturated and another new research topic comes up, such as mobile commerce, social commerce, sharing economy, and the latter is collaborative consumption. EC research increased for two decades from the 1995s. Then in the third decade, there was the emergence of new business models that are on-demand services (Laudon \& Traver, 2016). So that EC activity has declined due to a new business model that is different from the EC. This new business model will be explained in the literature review section on SE and CC.

From 562 articles of EC past studies (1989-present), the EC can be divided into three periods, first is the web commerce periods, latter is mobile commerce, and last is social commerce. Web commerce is indirect commercial activity through the website network. While mobile commerce (m-commerce) refers to a business transaction using a mobile application. M-commerce is more flexible and accessible rather than EC. The last, social commerce (s-commerce) is seller and buyer using social media as a tool to interact and transaction. People interest and want to participate in social media due to familiarity and personal. Scommerce is the early stage of SE. The similarity between S-commerce and SE is the primary activity based on social and economy motives.

The following map (depicted in figure 3) describes the term that usually used in sharing economy studies. We utilise VOSviewer software to mapping 562 papers. The map shows several colors, and the color symbolizes a different meaning and different cluster.

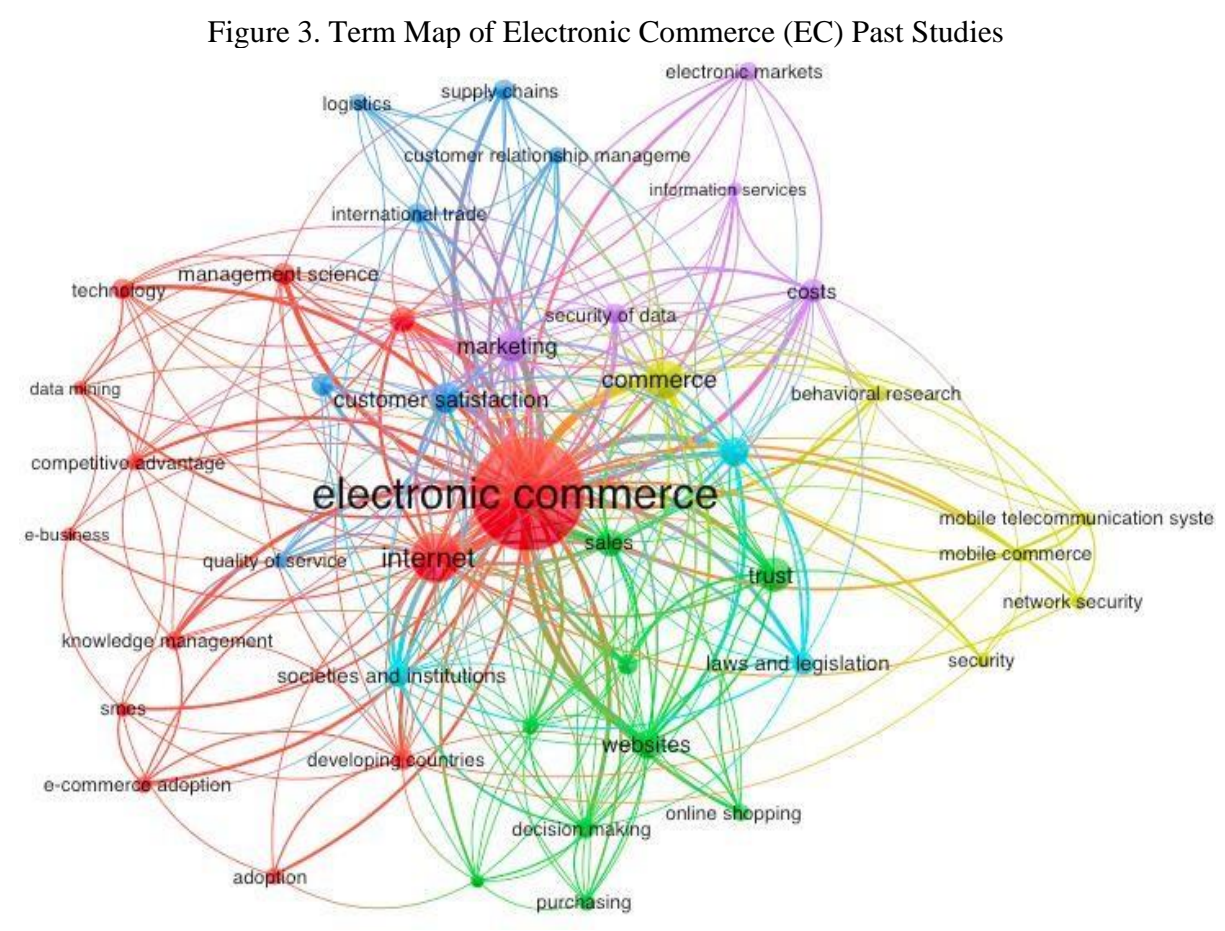

Source: Author calculations

Based on the figure (3), according to the colors that show on the map, there are five clusters marked by the different color red, green, purple, yellow and blue. We are focusing on the top three that the most informative colors: red, green, and blue. The red color, EC linked with Internet, technology, data mining, e-business, and adoption. We consider that the red group is ICT group. The green color relates to sales, law and legislation, purchasing, online shopping, trust, and decision-making. Then we mention the green group 
as a business group. The elements of blue color are logistic, supply chain, customer relationship management, quality of service, and customer satisfaction. The blue color refers to the value chain group.

The result of VOSviewer indicates that EC associated with ICT, business, and value chain. The ICT term describes technology based on Internet usage in EC, and it means that EC related to the platform usage. Further, the business group linked to sales and purchasing. This indicates that EC obtains financial compensation from the trading activity.

\section{Sharing Economy}

The decline in the number of studies on EC is due to the growth of new business models. This new business model arises because of the presence of tools and applications of web 2.0 that provides the opportunity for users to share photos and videos through social media networks, blogs, and sites. The deployment of social media and platform raises social commerce and sharing economy (Mauri, Minazzi, NietoGarcía, \& Viglia, 2018). The transaction occurs when social interaction among individuals is the similarity between SE and social commerce, but SE is not focusing on ownership transfer rather than social commerce (Puschmann \& Alt, 2016). Therefore, that gave rise to sociological, technological, and business phenomena (Laudon \& Traver, 2016). Those three phenomena create on-demand services that cannot be explained by EC. The new business model called the sharing economy. The following figure (4) describes the trend of sharing economy publications from 369 articles of SE.

Figure 4. Sharing Economy Publications Trend

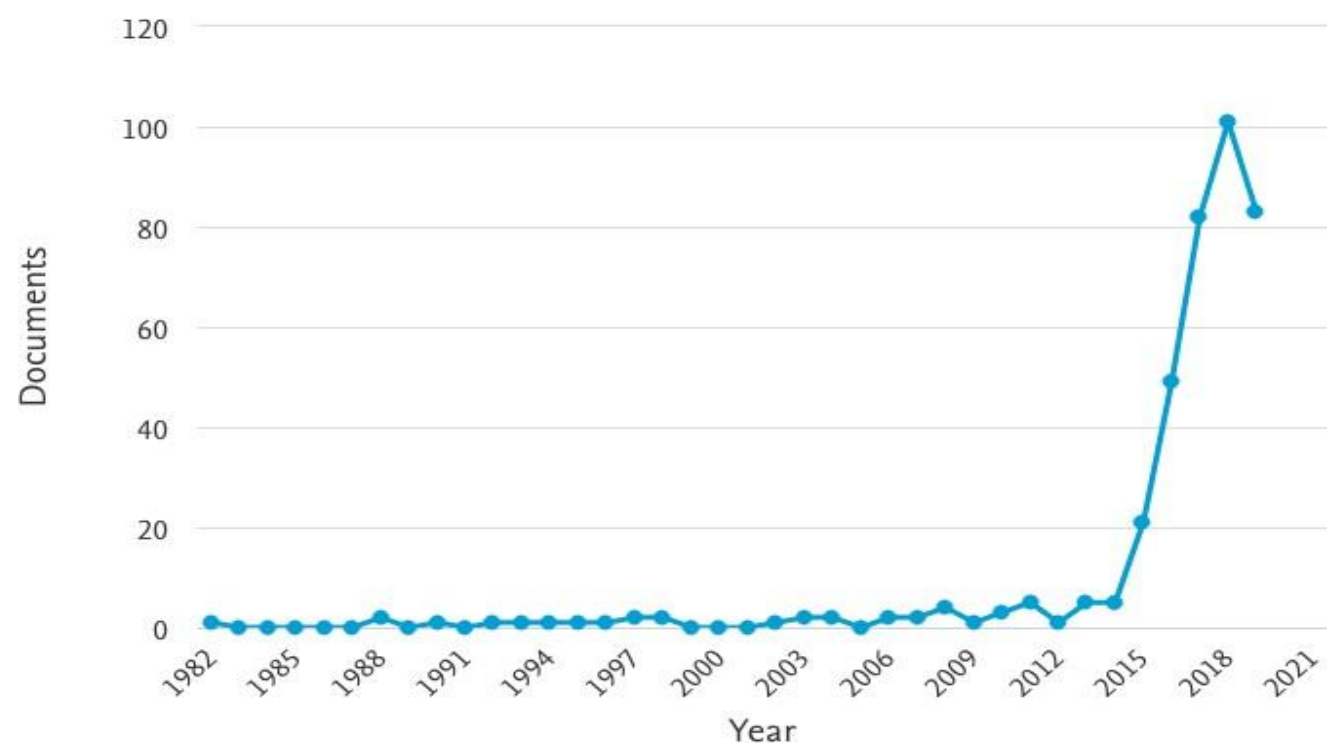

\section{Source: Author calculations}

Based on the figure 4, in 1982s to 2012s, the research of SE was rarely. However, the number of SE articles is significantly rising in 2015 s until the present. We can explain that SE research is on-trend. The earliest period from 1982s to 2012s, mostly the research explores in risk sharing, cost sharing, and profit sharing. The latter in 2013s, the term of sharing economy evolve in accordance with the existences of Uber and Airbnb.

Further, VOSviewer software is using to analyze all keywords in article title and abstract from 369 articles of SE. Depicted in figure (6), the results of VOSviewer software are twenty keywords appears and minimum seven times repeatedly. 


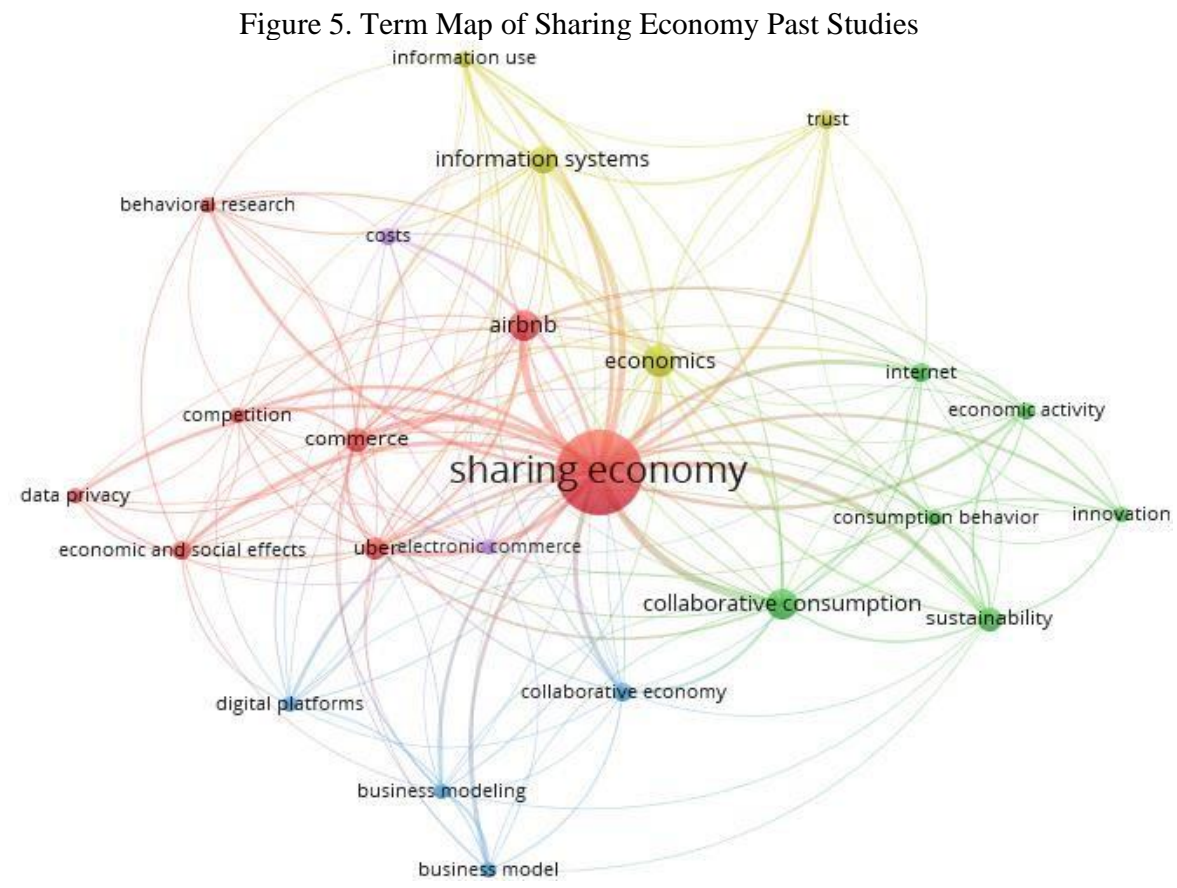

Source: Author calculations

Based on the figure (5), the colours describe the cluster and the volume of the circle explains the quantities of term usage. The bigger the circle, the more a term used in the studies. The map shows that SE related to collaborative consumption, Uber, Airbnb, commerce, economics, and Internet. It means that Uber and Airbnb are the most case studies used in SE research. SE also closely related to collaborative consumption, many scholars assume $\mathrm{CC}$ is part of SE. Commerce, Internet, and economics become the term that is repeatedly using in SE studies. Those of three words represent that SE activity using the Internet to interact and to obtain monetary rewards from commerce and the actor has economic motives to participate in SE. To clear up the distinction of SE and CC, first we explore the elements of SE from the definition that mention in SE papers. The next table show SE definition from several authors. 
TABLE 1.

SHARING ECONOMY CONCEPT

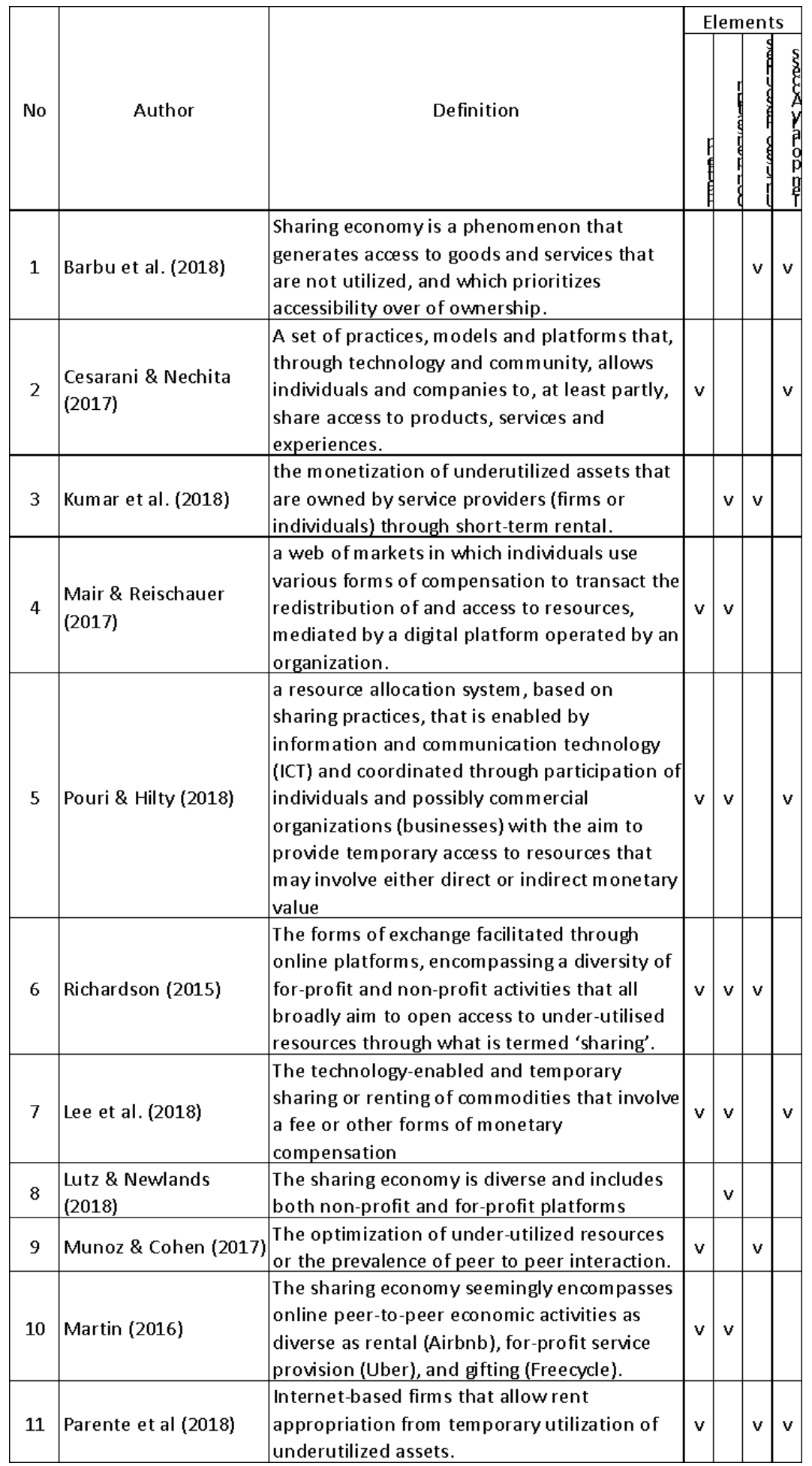

The table describes definition of SE from several authors. According to the definitions, there are four keywords mostly used to define SE: Technology platform, Un-used Resources, Compensation, and Temporary Access. (1) Technology Platform: The spread of Internet network and social media creates a transition of sharing from a conventional to digital sharing. The term of sharing economy appears in the Internet age [6]. Today, the Internet network in the form of platform used for sharing activity as the market mediation among the actors. (2) Un-used Resources: SE results from the economic crisis and global warming, so that motivates people to share underutilized resources than buying or owning the product or services (Barbu, Florea, Ogarcă, \& Răzvan Barbu, 2018). (3) Compensation: Compensation is the result 
of resource exchange among the actors; the form of compensation can be monetary or nonmonetary (Barbu et al., 2018; Lee, Chan, Balaji, \& Chong, 2018). Another study mentions profit or non- profit compensation (Pouri \& Hilty, 2018; Richardson, 2015). (4) Temporary Access: The transition of consumer behavior from buying to share underutilized resources, causing the consumer pays for access to product or service not for owning, this is means that the customer used the product or service in short or long-term (Lee et al., 2018; Lutz \& Newlands, 2018).

\section{Collaborative Consumption}

The last term is collaborative consumption, this term known since 1978 by Felson \& Spaeth. The research topic of CC after 1978 tended to be stagnant, but in the 2000s, the CC phenomenon reappeared as a response to new business models and activities that could not be explained by the EC (Figure 6). CC is different from SE, to distinguish the two-terms, we can see in figure 7. The picture shows the result from VOSviewer software and mentions ownership as keywords that most previous studies used it, also represent the character of CC. We argue that CC is including ownership transfer while SE that can only access the resources. However, Botsman \& Rogers (2010) mention Felson \& Spaeth definition is part of sharing activity, not CC. According to (Botsman \& Rogers, 2010a), CC is "people organizing the acquisition and distribution of resource for a fee or other compensation". The following figure (depicted in figure 6) describes the number of CC publications from 1978s to the present.

\section{Figure (6) Publication of Collaborative Consumption Topics}

\section{Documents by year}

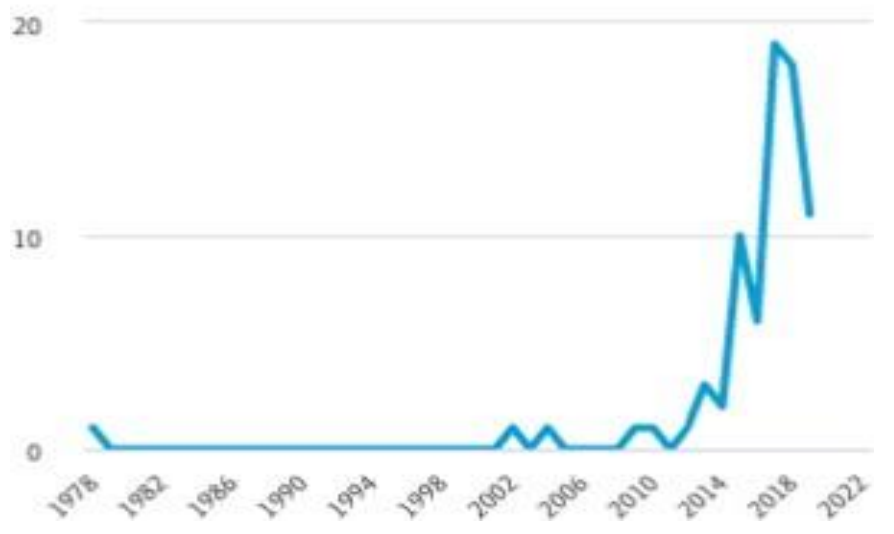

\section{Source: Author calculations}

The figure shows that $\mathrm{CC}$ publication still lack comparing to SE publications. CC trends still growing and interesting to discuss. CC introduces by Felson and Spaeth in 1978s and comes up again after 22 years later in the 2010s. In the 2008s, global warming issues and economic crisis affects the shifting of consumer behavior from owning new product or services to sharing the (Ganapati \& Reddick, 2018), so that CC began to arise in the 2010s. Later, we look forward the keywords that repeatedly used in CC studies. The next figure (depicted in figure 7) is the results using VOSviewer software to analyzing 70 selected papers of CC. 


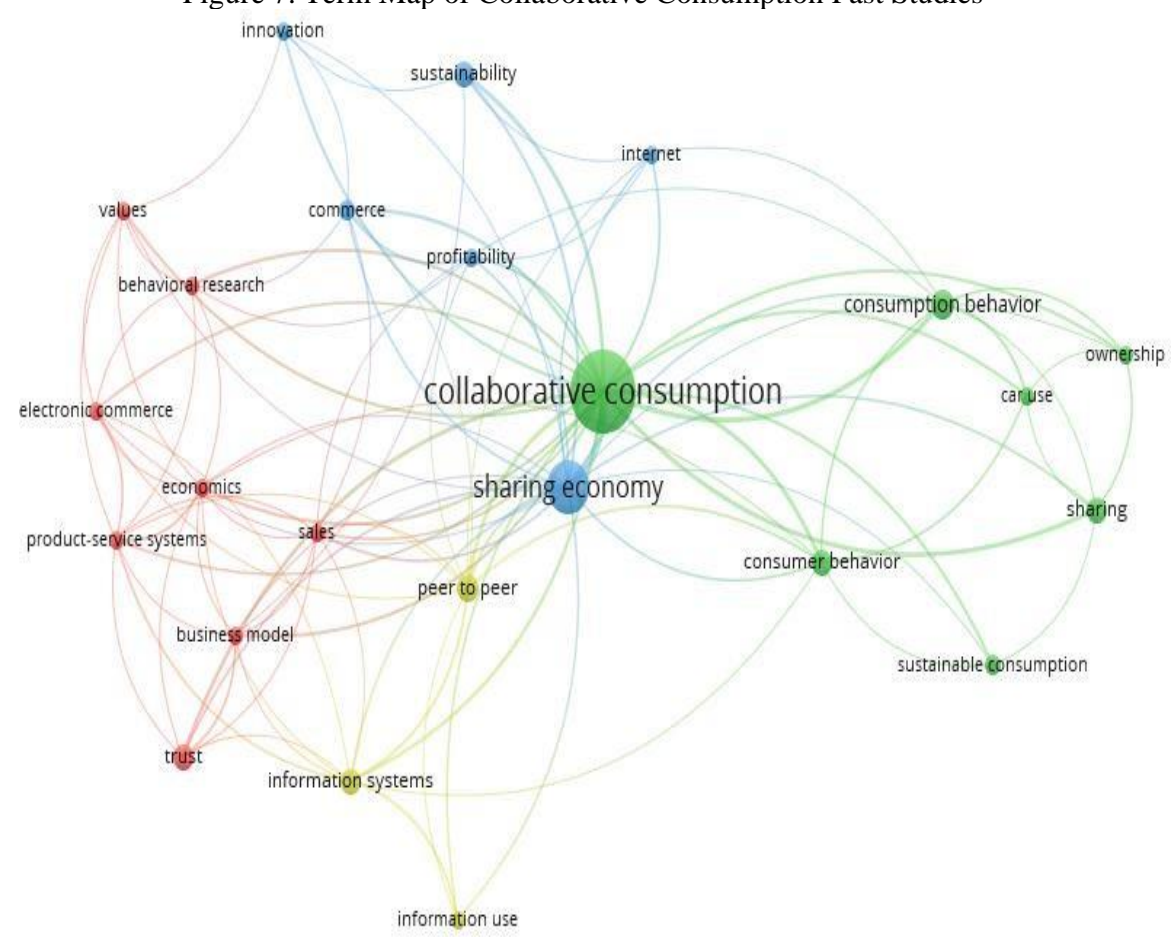

Source: Author calculations

As we have seen in figure 7, there are four clusters represent into four colors: green, blue, yellow, and red. The red cluster consists of values, trust, business model, electronic commerce, economics, productservice systems, sales, and behavior research. The red cluster describes that $\mathrm{CC}$ related to e-commerce. Trust and sales become the basic principles of E-commerce, also using in CC studies. Then the blue cluster composes of innovation, commerce, sustainability, profitability, and the Internet. It means that $\mathrm{CC}$ is the digital business motivated by the awareness of sustainability and commonly profit-oriented. The green cluster consists of consumer behavior, consumption behavior, sustainable consumption, sharing, ownership, and car use. The green cluster describes sustainability motive is a primary reason that consumption behavior shifting from possessing to sharing consumption.

Furthermore, the following table (table 2) is the list of collaborative consumption definition from several authors. The CC definition helps to clarify and to distinguish with SE concept. 
TABLE 2.

COLLABORATIVE CONSUMPTION CONCEPT

\begin{tabular}{|c|c|c|c|c|c|c|}
\hline \multirow[b]{2}{*}{ No } & \multirow[b]{2}{*}{ Author } & \multirow[b]{2}{*}{ Definition } & \multicolumn{4}{|c|}{ Elements } \\
\hline & & & $\begin{array}{l}E \\
\frac{E}{0} \\
\frac{+}{\pi} \\
\frac{\pi}{\alpha} \\
\end{array}$ & 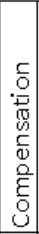 & 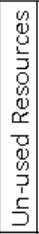 & 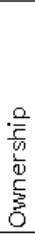 \\
\hline 1 & Belk (2014) & $\begin{array}{l}\text { People coordinating the acquisition and distribution } \\
\text { of a resource for a fee or other compensation. By } \\
\text { including other compensation, the definition also } \\
\text { encompasses bartering, trading, and swapping, } \\
\text { which involve giving and receiving non-monetary } \\
\text { compensation. }\end{array}$ & & $v$ & & \\
\hline 2 & Benjaafar (2015) & $\begin{array}{l}\text { New ways of peer-to-peer sharing that are voluntary } \\
\text { and enabled by internet-based exchange markets } \\
\text { and mediation platforms. }\end{array}$ & $\mathrm{v}$ & $\mathrm{v}$ & & \\
\hline 3 & Ertz et al. (2016) & $\begin{array}{l}\text { The set of resource circulation systems which enable } \\
\text { consumers to both obtain and provide, temporarily } \\
\text { or permanently, valuable resources or services } \\
\text { through direct interaction with other consumers or } \\
\text { through a mediator. }\end{array}$ & & & & v \\
\hline 4 & $\begin{array}{l}\text { Wahlen \& Laamanen } \\
\text { (2017) }\end{array}$ & $\begin{array}{l}\text { A form of economic collaboration where idling } \\
\text { resources are made available - shared - with others } \\
\text { in a larger community - the sharing economy. }\end{array}$ & & & $\mathrm{v}$ & \\
\hline 5 & Bae \& Koo (2018) & $\begin{array}{l}\text { Transactions consist not of ownership but of access, } \\
\text { such as in renting, lending, subscribing, reselling, } \\
\text { swapping, or even donating. }\end{array}$ & & & & v \\
\hline 6 & Lindblom et al., (2018) & $\begin{array}{l}\text { Collaborative consumption as } \mathrm{C} 2 \mathrm{C} \text { trading that } \\
\text { includes transfer of ownership. }\end{array}$ & & & & v \\
\hline 7 & $\begin{array}{l}\text { Hwang \& Griffiths } \\
\text { (2017) }\end{array}$ & $\begin{array}{l}\text { Collaborative consumption, which is facilitated } \\
\text { through networked technology and accessible } \\
\text { through mobile and computer devices, satisfies } \\
\text { consumers' diverse needs without the need for } \\
\text { purchase/ ownership. }\end{array}$ & $\mathrm{v}$ & & & v \\
\hline 8 & Rivera et al. (2017) & $\begin{array}{l}\text { The technological and material conditions of } \\
\text { possibility for peer-to-peer social interactions in one } \\
\text { ambit of the sharing economy. }\end{array}$ & $\mathrm{v}$ & & & \\
\hline 9 & Roos \& Hahn (2017b) & $\begin{array}{l}\text { Acquiring or providing resources from or to others } \\
\text { for collaborative, shared use among consumers or } \\
\text { peers as opposed to acquiring or providing new } \\
\text { resources for private use. }\end{array}$ & & & & v \\
\hline 10 & Pizzol et al. (2017) & $\begin{array}{l}\text { Collaboration between individuals and enabled } \\
\text { primarily by virtual platforms. }\end{array}$ & $\mathrm{v}$ & & & \\
\hline 11 & $\begin{array}{l}\text { Barnes \& Mattsson } \\
(2016)\end{array}$ & $\begin{array}{l}\text { The use of online marketplaces and social } \\
\text { networking technol ogies to facilitate peer-to-peer } \\
\text { sharing of resources (such as space, money, goods, } \\
\text { skills and services) between individuals, who may be } \\
\text { both suppliers and consumers." As the definition } \\
\text { implies, individual in collaborative consumption are } \\
\text { prosumers - both producers and consumers. }\end{array}$ & $\mathrm{v}$ & $v$ & & \\
\hline 12 & $\begin{array}{l}\text { Perren \& Grauerhol z } \\
\text { (2015) }\end{array}$ & $\begin{array}{l}\text { Collaborative consumption is also referred to as the } \\
\text { 'sharing economy' because individuals are sharing } \\
\text { access to resources (for a fee or other } \\
\text { compensation), or 'peer-to-peer' exchange because } \\
\text { both the service provider and recipient are } \\
\text { individuals rather than businesses. }\end{array}$ & & $\mathrm{v}$ & & \\
\hline
\end{tabular}

The three elements of CC: Platform, compensation and un-used resources are similar to the SE concept, the last element we mention ownership rather than temporary access. A certain number of CC definitions states that CC not only for temporary access but also the resources can be owned by the actor. (1) Platform: $\mathrm{CC}$ is an internet-based business model that can be accessed through a computer or mobile device (Hwang \& Griffiths, 2017). CC using the platform as a mediator to interact and transaction among the actor in a virtual practice (Benjaafar, Kong, Li, \& Courcoubetis, 2015; Pizzol, de Almeida, \& Soares, 2017). CC practice also still operates in offline activity (Roos \& Hahn, 2019). (2) Compensation: CC is a reciprocal 
activity that receiving for monetary or non-monetary compensation (Barnes \& Mattsson, 2016; Belk, 2014; Roos \& Hahn, 2019). Non-monetary compensation is the factor that differentiates SE and CC from EC. (3) Un-used resources: CC also utilize idle resources that mention by (Laamanen, Wahlen, \& Campana, 2015). (4) Ownership: Most of the authors mention that CC is not involved with ownership transfer (Guyader, 2018; Hwang \& Griffiths, 2017; Laamanen et al., 2015; Laamanen, Wahlen, \& Lorek, 2018) the other past studies argue that CC was involved in ownership transfer (Bae \& Koo, 2018; Ertz, Durif, \& Arcand, 2016; Lindblom, Lindblom, \& Wechtler, 2018; van de Glind, 2013).

\section{Methodology}

Several data source can provide information and data to analyse the relationship between CC, SE, and EC. Google Scholar (GS), Web of Science (WOS), and Scopus are examples of the data source. GS provides the number of references broader than Scopus or WOS (Bergman, 2012; Martín-Martín, Orduna-Malea, Thelwall, \& Delgado López-Cózar, 2018). However, GS has several limitations, such as inadequate quality control of references. Further, GS repeatedly records the same paper so that the scholars should spend more time to remove low-quality publication and clean up double record paper (Harzing \& Alakangas, 2016; Bergman, 2012). We choose Scopus as the data source, accordingly to Bergman (2012); Scopus is more informative and robust rather than WOS, particularly in Social Welfare area.

The methodology of this study has four steps: data searching, data selecting, data processing and data analyzing. We collected the data from Scopus. Scopus has comprehensive and robust data sources. Data searching using three keywords: "E-commerce", "Sharing Economy", and "Collaborative Consumption". We selected in three stages: first, we search for "e-commerce" or "electronic commerce limited to title, keyword, abstract, Englishlanguage, and article and conference paper of document types. We found 1.156 articles of EC, and then we reduce by subject area: business, management, and accounting; Arts and Humanities; Economics, Econometrics and Finance. Finally, we select 562 articles and paper of EC. The second stage is "Sharing Economy" keywords; we restricted to title, abstract, keywords. We identified 417 articles on SE. Then we made another limitation: the English language and document types of conference paper and articles. Last selection of SE articles is 369 articles. The last stage is searching using "collaborative consumption" keywords. Process selection similar to SE, we found 70 articles of CC.

Afterwards, we continue to process the data; the data process is listing and comparing the concept of CC and SE manually to understand the two uniqueness characteristics. EC concept is not elaborate in detail because the closest terms are CC and SE, so the concept needs to be compared, while EC is indeed different from the two. Later, find the keywords that repeated more than two times in the previous studies to recognize trend topics of EC, SE, and CC using VOSviewer software VOSviewer is software that generates a cluster map of an item. The items can be a form of publications, researchers, or terms that we will explore. We used terms to investigate further, and the terms are Collaborative consumption, sharing economy, and e-commerce. The cluster is a collection of keywords most often used that are related to each other in one group and also, different colors mark clusters. We combine the concept of CC, SE, and EC manually with the VOSviewer software to reassure the different characteristics of the three concepts. The last step is to generate a positioning map to categories EC, SE, and CC. A positioning map will be interpreted in data analysis. 


\section{Result and Discussion}

In this study, the three dimensions selected from the past studies of SE and CC: Platform usage, Compensation, and Ownership. The analysis divided into two sections; in the first section of the analysis, we focus on the platform usage and compensation dimension to generate the positioning map. Then, we discuss in detail the ownership dimension to make a clear position between SE and CC.

\section{Compensation and Platform Usage}

The activity of CC and SE had already done before the internet age and increase rapidly when internet technology is growing (Belk, 2014; Felson \& Spaeth, 1978). Recently, both business models are using a platform to facilitate the activities among actors. Despite CC and SE are recently based on the platform, but the traditional (non-internet- based) of CC and SE are continuing in use (Roos \& Hahn, 2019), therefore in this study we divided platform usage dimension into two categories: Platform and Nonplatform. Beside the platform dimension, compensation also separates into three categories: monetary compensation, non-monetary compensation, and without compensation. According to Belk (2014), CC is used for receiving and distributing resources delivering financial or non-financial compensation. While, SE refers to the activities to share idle resources with or without receiving any compensation (Lutz \& Newlands, 2018). In the other side, (Cherry \& Pidgeon, 2018) mention that the latest SE definition commonly for-profit sharing. Hence, we select three categories of compensation.

Figure 8. Positioning Map of EC, SE, and CC based on Compensation and Platform Dimensions

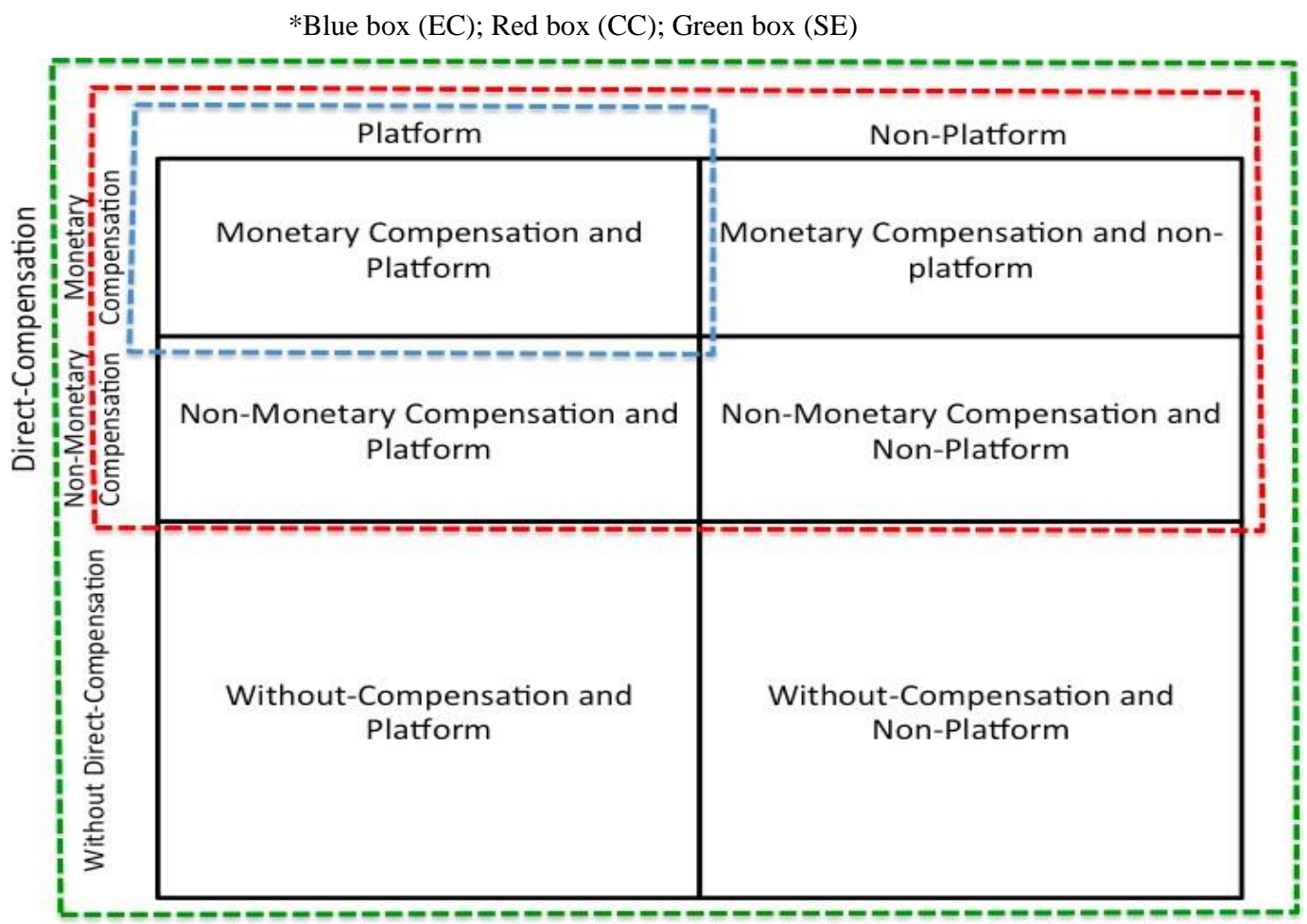

Source: Author calculations

Figure (8) describes the positioning map of EC, SE, and CC. The map consists of six model of transactions based on platform usage and compensation dimension. EC position depicted in the blue box of the map, according to Turban et al. (2018), EC is a virtual place using the Internet or another network in 
which seller and buyer, indirect meeting to make a transaction for profit-oriented. Therefore, the characteristic of EC based on Platform and compensation is monetary compensation and platform. It means that $\mathrm{EC}$ is a trading activity through the platform and receiving monetary benefit.

The red box positioning is for $\mathrm{CC}$. $\mathrm{CC}$ has broader characteristics than EC. CC has four models of transaction: monetary compensation and platform, monetary compensation and non-platform, nonmonetary compensation and platform, non-monetary compensation and non-platform. CC practice can be an online or offline business model (Roos \& Hahn, 2019) and receiving for monetary or non-monetary compensation (Belk, 2014). There is a similarity between the EC and $\mathrm{CC}$ in term of monetary compensation and platform model. To distinguish how EC and CC operate the term is from the transaction. The transaction of EC is trading new product while CC is an underused product resale or redistribution. The other transaction on $\mathrm{CC}$ is swapping and bartering for non-monetary compensation. The term of transaction is not limited for financial-based transaction but also involves non-monetary (Acquier, Daudigeos, \& Pinkse, 2017).

Finally, the SE position describes in the green box. The primary motivation for true sharing is helping and making connection among the actor (Belk, 2014), those motivations known as altruism motive and social motive. Sharing practice transforms from altruism and social motives to economic motives. Belk (2014) called pseudo-sharing for sharing practice base-on economic motivation. The practice sharing of SE includes true sharing and pseudo-sharing, form gift-giving to market-based orientation (Arun Sundararajan, 2016). SE consist of six transactions: without compensation and platform; without compensation and non-platform; monetary compensation and platform; non-monetary and platform; monetary compensation and non-platform; non-monetary compensation and non-platform. Uber and Airbnb are taken into-account as case study in SE previous research. We assume that SE transaction is renting and lending for monetary or other compensation; gift giving and donating included in SE transaction for non-compensation based.

\section{Ownership}

Beside platform and compensation, product ownership can be an indicator to differentiate between EC, SE, and CC. The positioning map of EC, SE, and CC can be seen in figure 9. The Ownership dimension has two categories: exchange-based and access-based activity. Access-based is related to the transfer of ownership from one party to another party. While Exchange-based refers to one party providing access to resources that can be used temporarily by another party or we can mention as a temporary ownership. 


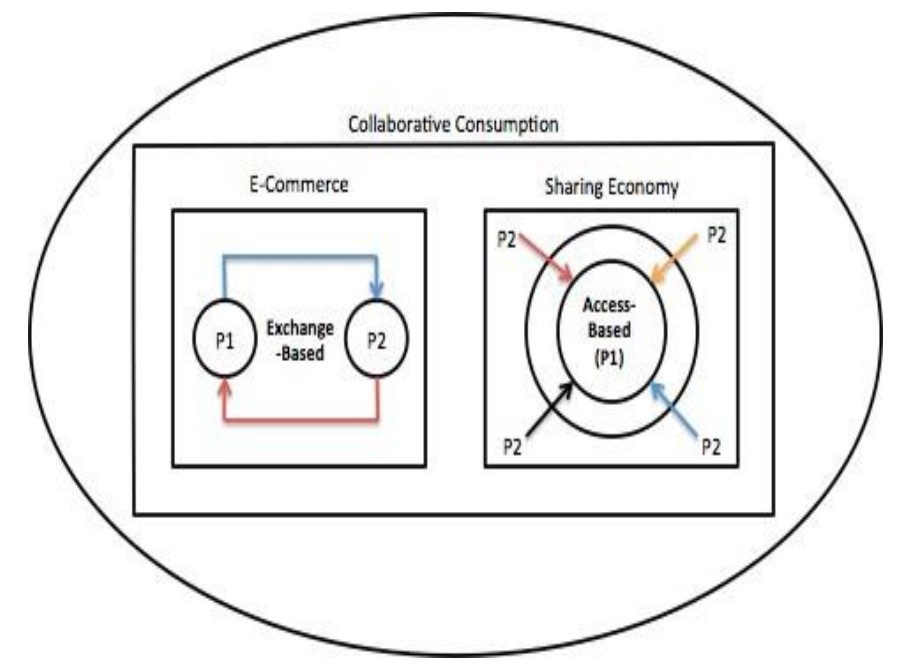

Source: Author calculations

The seller delivers the product to the buyer after dealing transaction in EC. Therefore, EC representatives as ownership transfer. Later, the consumption behavior is shifting from possessing the product to temporary use. SE is a new business model offering the service to access resources. The past studies mention SE is the non-ownership transfer of products and services (Acquier et al., 2017; Arun Sundararajan, 2016; Barbu et al., 2018; Puschmann \& Alt, 2016). Consumer pays for temporary utilization instead of ownership of commodities (Lee et al., 2018; Parente, Geleilate, \& Rong, 2018; Pouri \& Hilty, 2018). We consider that SE focus on access-based to resources rather than ownership transfer.

The similarity concept of SE and CC in defining the business model creates a puzzle to distinguish both models. Some past studies state CC transaction is not ownership but access to goods and services (Bardhi \& Eckhardt, 2012; Hwang \& Griffiths, 2017; Plenter et al., 2017). The other past studies mention CC includes ownership transfer (Gheitasy et al., 2015; Habibi, Davidson, \& Laroche, 2017; Lindblom et al., 2018). According to Botsman \& Rogers (2010), three types of CC are Product service system, redistribution, and a collaborative lifestyle. Redistribution refers to exchange activity that needs transferring ownership, and product service system is renting activity manage by company or peers. It means that the $\mathrm{CC}$ transaction involves access-based and ownership transfers.

The ownership transfer on EC and CC is closely related to each other, to differentiate between EC and $\mathrm{CC}$ is commodities. EC is commonly trading new commodities while $\mathrm{CC}$ is offering underused products to swaps or resale. Furthermore, CC also has similarity in access-based to resource concept with SE. According to Botsman \& Rogers (2010b), the Product service system is part of the CC model. It means that the access-based to resources in CC manage by a company, or we may say business to customer (B2C). Whilst, SE practice operates by peers or commonly mention as peer-to-peer (P2P) transaction.

\section{Conclusion}

Compensation, platform and ownership are the three dimensions that generate six models of transaction and build in a positioning map to identify EC, SE, and CC. EC and CC are compensation-based, while SE is with and without compensation-based. EC is platform-based and monetary compensation. SE has a broader concept than CC. CC has four models of transaction: monetary and non-platform, nonmonetary compensation and non-platform, monetary compensation and platform, non-monetary and 
platform. SE has six models of transaction: without compensation and platform, without compensation and non-platform, monetary and non-platform, non-monetary compensation and non-platform, monetary compensation and platform, non-monetary and platform. Further EC, SE, and CC identify through dimension of ownership. EC focus on ownership transfer from seller to buyer. Moreover, SE concentrates on access to resource. Whilst, CC operates two practices: access-based to resources and ownership transfer. We acknowledged several questions that cannot be answered by this study: (1) Related to the compensation and platform dimensions: (a) How can we differentiate between compensation and impacts that the actor receives from the CC activity? (b) How can we measure the compensation fairness in CC? $\mathrm{CC}$ is not a legal entity. Thus, how can one settle any dispute? (2) Concerning the consumer behavior in CC: (a) what are the theories that explain the platform user behavior in CC? (b) How value-exchanges occur on the CC platform? We would like to leave those questions to other scholars who are interested to continue our study. We hope that this paper has provided a clearer direction for the future study of CC.

\section{Blibliography}

Acquier, A., Daudigeos, T., \& Pinkse, J. (2017). Promises and paradoxes of the sharing economy: An organizing framework. Technological Forecasting and Social Change. https://doi.org/10.1016/j.techfore.2017.07.006

Arun Sundararajan. (2016). The Sharing Economy, Market Economies, and Gift Economies. The Sharing Economy, The End of Employment and the Rise of Crowd-Based Capitalism.

Bae, J., \& Koo, D. M. (2018). Lemons problem in collaborative consumption platforms: Different decision heuristics chosen by consumers with different cognitive styles. Internet Research. https://doi.org/10.1108/IntR-08-2017-0332

Barbu, C. M., Florea, D. L., Ogarcă, R. F., \& Răzvan Barbu, M. C. (2018). From ownership to access: How the sharing economy is changing the consumer behavior. Amfiteatru Economic. https://doi.org/10.24818/EA/2018/48/373

Bardhi, F., \& Eckhardt, G. M. (2012). Access-based consumption: The case of car sharing. Journal of Consumer Research. https://doi.org/10.1086/666376

Barnes, S. J., \& Mattsson, J. (2016). Understanding current and future issues in collaborative consumption: A four-stage Delphi study. Technological Forecasting and Social Change. https://doi.org/10.1016/j.techfore.2016.01.006

Becker-Leifhold, C. V. (2018). The role of values in collaborative fashion consumption - A critical investigation through the lenses of the theory of planned behavior. Journal of Cleaner Production. https://doi.org/10.1016/j.jclepro.2018.06.296

Belk, R. (2014). You are what you can access: Sharing and collaborative consumption online. Journal of Business Research. https://doi.org/10.1016/j.jbusres.2013.10.001

Benjaafar, S., Kong, G., Li, X., \& Courcoubetis, C. (2015). Modeling and analysis of collaborative consumption in peer-to-peer car sharing. Performance Evaluation Review. https://doi.org/10.1145/2847220.2847250

Botsman, R., \& Rogers, R. (2010a). What's Mine Is Yours - How Collaborative Consumption is Changing the Way we live. Business. https://doi.org/10.1016/S0168-9525(00)00086-X

Botsman, R., \& Rogers, R. C. N.-O. L. S. (STACK) H. . C. B. 2010. (2010b). The Rise of Collaborative 
Consumption. In What's Mine is Yours: how collaborative consumption is changing the way we live.

Cherry, C. E., \& Pidgeon, N. F. (2018). Is sharing the solution? Exploring public acceptability of the sharing economy. Journal of Cleaner Production. https://doi.org/10.1016/j.jclepro.2018.05.278

Dave Chaffey, Tanya Hemphill, D. E.-B. (2019). Digital Business and E-Commerce Management, 7th Edition. Pearson UK.

Davidson, A., Habibi, M. R., \& Laroche, M. (2018). Materialism and the sharing economy: A cross-cultural study of American and Indian consumers. Journal of Business Research. https://doi.org/10.1016/j.jbusres.2015.07.045

Dreyer, B., Lüdeke-Freund, F., Hamann, R., \& Faccer, K. (2017). Upsides and downsides of the sharing economy: Collaborative consumption business models' stakeholder value impacts and their relationship to context. Technological Forecasting and Social Change. https://doi.org/10.1016/j.techfore.2017.03.036

Ertz, M., Durif, F., \& Arcand, M. (2016). Collaborative consumption: Conceptual snapshot at a buzzword. Journal of Entrepreneurship Education. https://doi.org/10.2139/ssrn.2799884

Felson, M., \& Spaeth, J. L. (1978). Community Structure and Collaborative Consumption: A Routine Activity Approach. American Behavioral Scientist. https://doi.org/10.1177/000276427802100411

Ganapati, S., \& Reddick, C. G. (2018). Prospects and challenges of sharing economy for the public sector. Government Information Quarterly. https://doi.org/10.1016/j.giq.2018.01.001

Gheitasy, A., Abdelnour-Nocera, J., \& Nardi, B. (2015). Socio-technical gaps in online collaborative consumption (OCC): An example of the Etsy community. SIGDOC 2015 - Proceedings of the 33rd Annual International Conference on the Design of Communication. https://doi.org/10.1145/2775441.2775458

Guyader, H. (2018). No one rides for free! Three styles of collaborative consumption. Journal of Services Marketing. https://doi.org/10.1108/JSM-11-2016-0402

Habibi, M. R., Davidson, A., \& Laroche, M. (2017). What managers should know about the sharing economy. Business Horizons. https://doi.org/10.1016/j.bushor.2016.09.007

Hamari, J., Sjöklint, M., \& Ukkonen, A. (2016). The sharing economy: Why people participate in collaborative consumption. Journal of the Association for Information Science and Technology. https://doi.org/10.1002/asi.23552

Harzing, A. W., \& Alakangas, S. (2016). Google Scholar, Scopus and the Web of Science: a longitudinal and cross-disciplinary comparison. Scientometrics. https://doi.org/10.1007/s11192-015-1798-9

Heinrichs, H. (2013). Sharing economy: A potential new pathway to sustainability. GAIA. https://doi.org/10.14512/gaia.22.4.5

Hwang, J., \& Griffiths, M. A. (2017). Share more, drive less: Millennials value perception and behavioral intent in using collaborative consumption services. Journal of Consumer Marketing. https://doi.org/10.1108/JCM-10-2015-1560

Jiang, B., \& Tian, L. (2018). Collaborative consumption: Strategic and economic implications of product sharing. Management Science. https://doi.org/10.1287/mnsc.2016.2647

Laamanen, M., Wahlen, S., \& Campana, M. (2015). Mobilising collaborative consumption lifestyles: A comparative frame analysis of time banking. International Journal of Consumer Studies. https://doi.org/10.1111/ijcs.12190 
Laamanen, M., Wahlen, S., \& Lorek, S. (2018). A moral householding perspective on the sharing economy. Journal of Cleaner Production. https://doi.org/10.1016/j.jclepro.2018.08.224

Lasda Bergman, E. M. (2012). Finding Citations to Social Work Literature: The Relative Benefits of Using Web of Science, Scopus, or Google Scholar. Journal of Academic Librarianship.

https://doi.org/10.1016/j.acalib.2012.08.002

Laudon, K. C., \& Traver, C. G. (2016). E-commerce 2016: business. technology. society. In Global Edition.

Lee, Z. W. Y., Chan, T. K. H., Balaji, M. S., \& Chong, A. Y. L. (2018). Why people participate in the sharing economy: an empirical investigation of Uber. Internet Research. https://doi.org/10.1108/IntR-01-20170037

Lindblom, A., Lindblom, T., \& Wechtler, H. (2018). Collaborative consumption as C2C trading: Analyzing the effects of materialism and price consciousness. Journal of Retailing and Consumer Services. https://doi.org/10.1016/j.jretconser.2018.07.016

Lutz, C., \& Newlands, G. (2018). Consumer segmentation within the sharing economy: The case of Airbnb. Journal of Business Research. https://doi.org/10.1016/j.jbusres.2018.03.019

Martín-Martín, A., Orduna-Malea, E., Thelwall, M., \& Delgado López-Cózar, E. (2018). Google Scholar, Web of Science, and Scopus: A systematic comparison of citations in 252 subject categories. Journal of Informetrics. https://doi.org/10.1016/j.joi.2018.09.002

Martin, C. J. (2016). The sharing economy: A pathway to sustainability or a nightmarish form of neoliberal capitalism? Ecological Economics. https://doi.org/10.1016/j.ecolecon.2015.11.027

Mauri, A. G., Minazzi, R., Nieto-García, M., \& Viglia, G. (2018). Humanize your business. The role of personal reputation in the sharing economy. International Journal of Hospitality Management. https://doi.org/10.1016/j.ijhm.2018.01.017

Möhlmann, M. (2015). Collaborative consumption: Determinants of satisfaction and the likelihood of using a sharing economy option again. Journal of Consumer Behaviour. https://doi.org/10.1002/cb.1512

Parente, R. C., Geleilate, J. M. G., \& Rong, K. (2018). The Sharing Economy Globalization Phenomenon: A Research Agenda. Journal of International Management. https://doi.org/10.1016/j.intman.2017.10.001

Pizzol, H. D., de Almeida, S. O., \& Soares, M. do C. (2017). Collaborative consumption: A proposed scale formeasuring the construct applied to a carsharing setting. Sustainability (Switzerland). https://doi.org/10.3390/su9050703

Plenter, F., Fielt, E., Von Hoffen, M., Chasin, F., \& Rosemann, M. (2017). Repainting the Business Model Canvas for peer-to-peer sharing and collaborative consumption. Proceedings of the 25th European Conference on Information Systems, ECIS 2017.

Pouri, M. J., \& Hilty, L. M. (2018). Conceptualizing the digital sharing economy in the context of sustainability. Sustainability (Switzerland). https://doi.org/10.3390/su10124453

Puschmann, T., \& Alt, R. (2016). Sharing economy. Business and Information Systems Engineering. https://doi.org/10.1007/s12599-015-0420-2

Richardson, L. (2015). Performing the sharing economy. Geoforum. https://doi.org/10.1016/j.geoforum.2015.11.004

Roos, D., \& Hahn, R. (2019). Understanding Collaborative Consumption: An Extension of the Theory of Planned Behavior with Value-Based Personal Norms. Journal of Business Ethics. 
https://doi.org/10.1007/s10551-017-3675-3

Turban, E., Outland, J., King, D., Lee, J. K., Liang, T.-P., \& Turban, D. C. (2018). Social Commerce:

Foundations, Social Marketing, and Advertising. https://doi.org/10.1007/978-3-319-58715-8_8 van de Glind, P. (2013). The consumer potential of Collaborative Consumption. 